Original Article

\title{
DEVELOPMENT AND IN VITRO EVALUATION OF A NEW TOPICAL O/W EMULGEL FROM FRUIT EXTRACT OF PYRUS COMMUNIS
}

\author{
TANZILA KHILJEE, NAVEED AKHTAR
}

Department of Pharmacy, Faculty of Pharmacy and Alternative Medicine, the Islamia University of Bahawalpur, Bahawalpur Pakistan 63100 Email: tk_pharmacist786@yahoo.com

Received: 10 Aug 2018 Revised and Accepted: 22 Feb 2019

\begin{abstract}
Objective: The aim of the present study was to develop a new topical dosage form containing Pyrus communis fruit extract. Developed formulation was $\mathrm{O} / \mathrm{W}$ Emulgel which was evaluated by its in vitro tests and its stability studies at different storage conditions.

Methods: Hydroalcoholic Pyrus communis extract was prepared by the maceration process. A 4\% Pyrus communis emulgel was prepared by the combination of emulsion and gel at a specific temperature and mixing through homogenizers. The formulations having different concentration of carbopol 940 (gelling agent) were placed at $8{ }^{\circ} \mathrm{C}, 25^{\circ} \mathrm{C}, 40^{\circ} \mathrm{C}$ and $40{ }^{\circ} \mathrm{C}+75 \% \mathrm{RH}$ for 3 mo in order to find out the most stable formulation. After the selection of final emulgel formulation was eventually further evaluated for in vitro studies such as phase separation, centrifugation, rheology, $\mathrm{pH}$, conductivity, organoleptic properties and mean droplet size over a period of $12 \mathrm{w}$ at $8{ }^{\circ} \mathrm{C}, 25^{\circ} \mathrm{C}, 40^{\circ} \mathrm{C}$ and $40{ }^{\circ} \mathrm{C}+75 \% \mathrm{RH}$.
\end{abstract}

Results: In vitro evaluation of the selected Pyrus communis emulgel formulation showed good resistance to phase separation on centrifugation, conductivity gradually increases due to oil in water emulgel and $\mathrm{pH}$ of formulation was gradually decreased. The rheological behavior was nonNewtonian pseudoplastic and showed shear thinning fluid behavior. Mean droplet size of Pyrus communis emulgel was $16.0 \pm 0.20 \mu \mathrm{m}$ and after $90 \mathrm{~d}$ droplet size was $16.7 \pm 0.55 \mu \mathrm{m}$ at high storage temperatures at $40^{\circ} \mathrm{C}$ and $40^{\circ} \mathrm{C}+75 \mathrm{RH}$ and no significant changes were observed at normal storage conditions at $8{ }^{\circ} \mathrm{C}$ and $25^{\circ} \mathrm{C}$.

Conclusion: Pyrus communis emulgel fresh fruit extract showed stable formulation at different storage conditions. This new formulation will be a good addition to pharmaceutical dosage forms made from traditionally used plants.

Keywords: Pyrus communis, Emulgel, Stability testing, In vitro evaluation

(C) 2019 The Authors. Published by Innovare Academic Sciences Pvt Ltd. This is an open access article under the CC BY license (http://creativecommons.org/licenses/by/4.0/) DOI: http://dx.doi.org/10.22159/ijpps.2019v11i4.29063

\section{INTRODUCTION}

Fruits are an important part of our diet. It provides nutrition and energy to our body. Traditionally, different fruit extracts have been used in medicines for internal and external diseases as a remedy. Some fruits like pear are commonly used in Pakistan having many health benefits [1]. Diet-conscious peoples are taking it as it helps in the reduction of weight. This fruit has very less caloric content. It is rich of healthful components like carbohydrates, minerals, vitamins, protein, fat, fibers, etc. The peel and pulp show better phenolic constituents and Flavonoid as compared to seed of a pear [2]. Pyrus Communis has a better composition of Flavonoid contents, anthocyanin, tannins, and polyphenol. Pyrus Communis is a rich source of vitamin C, folic acid, dietary fiber, Potassium, Tyrosine, Aspartic acid. Natural bioactive agents are responsible for color, odor, appearance and taste of fruit [3-5].

Pyrus Communis was used in folk medicines as diuretics as it is rich in fiber and low in sodium. In diarrhea its astringent and antiseptic properties help in the treatment of colitis. It helps in cholesterol reduction so helps in controlling obesity, cardiovascular diseases and cancer. Also reported for laxatives, hypertension properties. It is very suitable diet for diabetics due to its low-calorie content. It has a high amount of potassium which, along with calcium, helps in bone formation and nervous systems. So help in the growth of children. After growth helpful in the maintenance of bones and nervous system. Due to rich sources of vitamin C it has strong antioxidant potential $[6,7]$.

Fruit Extract has been used topically by ladies in Pakistan as a scrubber. Fruit extract help in glowing of skin as acting as anti-aging and reduces wrinkles. It is a very good antiseptic and analgesic [7]. But unfortunately, no single pharmaceutical topical dosage form has been available yet having pear extract. Although many topical dosage forms having plant extracts had been formulated by different researchers like cream, ointment, gels and emulgel [8]. It is noted that emulgel is the best formulation as it is having both benefits of gel and emulsion. It has the best drug loading capacity and provides fast drug release from the formulation. Although it provides better penetration of drug to skin [9-11].

The present study aims to formulate water in oil emulgel having Pyrus communis plant extract. Formulation is tested for its stability under different temperature conditions. $0 / \mathrm{W}$ Emulgel qualifies the stability tests afterward the stable formulation is tested for other in vitro tests. The prepared formulation is the new topical dosage form having Pyrus communis extract and will be a promising addition in the health care system.

\section{MATERIALS AND METHODS}

\section{Chemicals}

The chemicals were purchased by Merck K GaA Darmstadt, Germany (Liquid paraffin, span 20, tween 20, propylene glycol, methyl parabin, analytical grade methanol, triethanolamine and carbopol 940). Water was distilled fresh from the laboratory.

\section{Apparatus}

Rotary evaporator (EYELA-CA-IIII, Rika-KiKai, Tokyo, Japan), pH meter (WTW pH-197i, Germany), Conductivity meter (WTW COND197i, Germany), Centrifugation machine (EBA 20. Hettich, Germany), Rheometer (DV-III Ultra, Brookfield engineering laboratory, USA), Optical microscope (Eclipse E200, Nikon, Japan).

\section{Fruit material}

The fresh whole fruit of Pyrus communis was used as the active drug agent for medicinal purposes. These were collected from Azad Kashmir. Then these fruits were identified from Quaid-I-Azam University in the department of plant sciences by Dr. Muhammad Zafar Ph. D. (QAU) Herbarium Botanist and voucher specimen's number certificate was 805 . 


\section{Preparation of Pyrus communis extract}

$1 \mathrm{~kg}$ fresh whole fruit except seed of Pyrus communis was cut into slices and then ground with $300 \mathrm{ml}$ of distilled water. A paste made and added $800 \mathrm{ml}$ analytical grade methanol to make final volume $1000 \mathrm{ml} .80 \%$ methanol and water $(\mathrm{v} / \mathrm{v})$ ratio mixture, covered with aluminum foil wrapping for $3 \mathrm{~d}$ at a $25{ }^{\circ} \mathrm{C}$ room temperature in a 5 liter beaker. The hydroalcoholic fruit extract was shaked after $24 \mathrm{~h}$ daily in order to improve the solubility of fruit constituents with solvents. The extract was obtained from the macerated mixture by filtration using muslin cloth. Then this filtrate was again passed through whattman no.1 filter paper for further filtration. The filtered extracts were concentrated and evaporated by using a rotary evaporator at a speed of $40 \mathrm{rpm}$ at the temperature of $40{ }^{\circ} \mathrm{C}$ and refrigerator (chiller) $5{ }^{\circ} \mathrm{C}$. The dried concentrated extract was stored in a refrigerator at $8{ }^{\circ} \mathrm{C}$ until used for further characterization study.

\section{Preparation of emulgel}

For emulsion preparation first of all measure the ingredients and then separately heat, oily phase and aqueous phase at $75^{\circ} \mathrm{C}$ and then mixes both phases and mixed them under a speed of $<70 \mathrm{rpm}$ in a homogenizer. Next Step was the preparation of gel. In-gel preparation measure the ingredient carefully and mixed $1.5 \%$ of cabopol940 in distilled water in a homogenizer at a gentle speed to make final weight $100 \mathrm{gm}$. When the gel was formed so add triethanolamine solution (pH adjusting agent) few drops to stable the gel at pH lie between 6.0-5.5 by using $\mathrm{pH}$ meter. Mix the emulsion, gel and 5\% Pyrus communis extract in a homogenizer at the speed of $2000 \mathrm{rpm}$ for $10 \mathrm{~min}$ and then reduced to $1000 \mathrm{rpm}$ for $5 \mathrm{~min}$ and again homogenized for $5 \mathrm{~min}$ at the speed of 500rpm. Final emulgel was prepared and cover the beaker with aluminum foil and placed at different temperatures $8{ }^{\circ} \mathrm{C}$, $25^{\circ} \mathrm{C}, 40^{\circ} \mathrm{C}$ and $40^{\circ} \mathrm{C}+75 \% \mathrm{RH}$.

\section{Stability studies}

Stability studies were performed in two stages i.e. one was done in two months and this period was called preliminary studies. The second was done in a two month period divided into different storage temperature, i.e. $8{ }^{\circ} \mathrm{C}, 25^{\circ} \mathrm{C}, 40^{\circ} \mathrm{C}, 50{ }^{\circ} \mathrm{C}$ and $40{ }^{\circ} \mathrm{C}+75 \mathrm{RH}$. Most stable finally selected emulgel was obtained from these studies and freshly prepared selected emulgel again kept for two months at different temperatures, i.e. $8{ }^{\circ} \mathrm{C}, 25{ }^{\circ} \mathrm{C}, 40{ }^{\circ} \mathrm{C}, 50{ }^{\circ} \mathrm{C}$ and $40{ }^{\circ} \mathrm{C}$ $+75 \%$ RH [12-14]. Base formulation (without Pyrus communis extract) is also tested for its stability under all these conditions.

\section{Data analysis}

All the results are presented as a mean \pm standard deviation (SD). Image analyzing software (Digimizer) was used to perform particle size analysis. One way analysis of variance (ANOVA) was used to analyze the data for rheology. The level of significance adopted was $\mathrm{p}<0.05$.

\section{In vitro characterization of Pyrus communis extract based emulgel}

\section{pH}

This test was performed by dipping lope of $\mathrm{pH}$ meter in the formulation. Formulation and base $\mathrm{pH}$ was observed at $8{ }^{\circ} \mathrm{C}, 25^{\circ} \mathrm{C}$, $40{ }^{\circ} \mathrm{C}, \quad 40{ }^{\circ} \mathrm{C}+75 \%$ RH temperature conditions. Beakers of formulation and base were covered with aluminum foil and placed at different temperature for three month study periods.

\section{Conductivity}

Conductivity test was carried out by placing lope of conductivity meter into the beakers which were filled by formulation at different storage conditions. A probe of Electrical conductivity meter was dipped into the formulation until a stable reading was measured and the average value was noted down.

\section{Centrifugation}

Centrifugation test was carried out by placing $2 \mathrm{~g}$ of formulation and base, stored at different conditions, in the $15 \mathrm{ml}$ centrifuge tube and centrifuged for two runs of $10 \mathrm{~min}$, at $5000 \mathrm{rpm}$. At the end of each cycle, tubes were investigated macroscopically for the presence of any possible phase separation.

\section{Rheology}

Rheological properties of the formulation were investigated using a cone and plate type rheometer equipped with a circulating system for temperature control. Rheological measurements were made at $25 \pm 1^{\circ} \mathrm{C}$ using a CP41 spindle. Shear rate was progressively increased from 20$86 / \mathrm{s}$ to construct the rheograms and data obtained was mathematically analyzed by a Brookfield programme, Rheocalc version V 1.01 according to the power law analysis as mention in equation 2

$\mathrm{T}=\mathrm{KDn}$

Where $\mathrm{T}$ is shear stress, $\mathrm{D}$ is the shear rate; $\mathrm{K}$ is consistency index and $\mathrm{n}$ is the flow index [14].

\section{Microscopic evaluation}

The emulgel morphology and particle size were described by an optical microscope coupled to a high-resolution digital camera. Micrographs were collected by using Mnisee version 1.1 Image analyzing software, at $100 \mathrm{x}$ magnification. A small quantity of w/o emulsion was smeared on the glass slide and diluted it with external phase. Samples were covered slip with care to avoid sample damage by shear stress. The mean droplet size was reported by using calibrated ocular micrometer. The data were obtained from 20 various micrographs of the sample.

\section{RESULTS}

pH

The $\mathrm{pH}$ was observed to the Pyrus communis emulgel for the $12^{\text {th }}$ week study period. The $\mathrm{pH}$ of freshly prepared Pyrus communis emulgel was 5.87 which were decreased to 5.00 after the $12^{\text {th }}$ week of the study period as shown in table 1 . Base $\mathrm{pH}$ was higher than formulation $\mathrm{pH}$.

\section{Conductivity}

The freshly prepared Pyrus communis emulgel had conductivity was $90.79 \mu \mathrm{S} / \mathrm{cm}$ which increased with the passage of time to $225 \mu$ $\mathrm{S} / \mathrm{cm}$ after $12^{\text {th }}$ weeks as shown in table 1 . Higher increased was observed at $40{ }^{\circ} \mathrm{C}$ and $40{ }^{\circ} \mathrm{C}+75 \% \mathrm{RH}$. The less increased was observed at $8{ }^{\circ} \mathrm{Cand} 25^{\circ} \mathrm{C}$. Formulation showed less conductivity than the base.

\section{Centrifugation}

Pyrus communis formulation and the base was kept at $8{ }^{\circ} \mathrm{C}, 25^{\circ} \mathrm{C}, 40$ ${ }^{\circ} \mathrm{C}$ and $40{ }^{\circ} \mathrm{C}+75 \% \mathrm{RH}$ storage conditions and it is observed that formulation placed at $8{ }^{\circ} \mathrm{C}$ and $25{ }^{\circ} \mathrm{C}$ did not show any phase separation at the complete period of study. Formulation at high temperature $40{ }^{\circ} \mathrm{C}$ and $40{ }^{\circ} \mathrm{C}+75 \% \mathrm{RH}$ was shown little effect on it as slight phase separation was observed after the $12^{\text {th }}$ week of the study period. The Pyrus communis emulgel showed better long term stability as no phase separation was observed. Similarly, base also did not show any phase separation.

\section{Rheology}

The relationship between shear rate and viscosity for formulations at various conditions after different time interval was shown that flow curves were non-linear which showed the non-Newtonian, the pseudo plastic behavior of formulation during the study period. Such characteristic was desirable in the topically applied formulations which were used in pharmaceutical and cosmetic products. The values of rheological parameters are shown in table 2. The consistency index (CI), flow index (FI) and confidence of fit were shown in the table. Power law analysis method was used in this study.

\section{Microscopic evaluation}

The photomicrographs of freshly prepared Pyrus communis emulgel and after the $12^{\text {th }}$ week in various storage conditions were shown in fig. 1 . The freshly prepared Pyrus communis emulgel droplets were spherical in shape. The shape of the particles was not changed in the $12^{\text {th }}$ week of the study period. The mean droplet size of emulsion was found to be within macroemulsion range (1-100 um) for $12^{\text {th }}$ week of study periods which kept at different temperature and humidity conditions. 
Table 1: $\mathrm{pH}$ and Conductivity at $8{ }^{\circ} \mathrm{C}, 25^{\circ} \mathrm{C}, 40{ }^{\circ} \mathrm{Cand} 40^{\circ} \mathrm{C}+75 \% \mathrm{RH}$ of Pyrus communis emulgel, after $30 \mathrm{~d}$, after $60 \mathrm{~d}$ and after $90 \mathrm{~d}$

\begin{tabular}{|c|c|c|c|c|c|c|c|c|}
\hline \multirow{3}{*}{$\begin{array}{l}\text { Reading } \\
\text { schedule }\end{array}$} & \multicolumn{8}{|l|}{ pH } \\
\hline & \multicolumn{2}{|l|}{$8^{\circ} \mathrm{C}$} & \multicolumn{2}{|l|}{$25^{\circ} \mathrm{C}$} & \multicolumn{2}{|l|}{$40^{\circ} \mathrm{C}$} & \multicolumn{2}{|c|}{$40{ }^{\circ} \mathrm{C}+75 \% \mathrm{RH}$} \\
\hline & B & $\mathbf{F}$ & B & $\mathbf{F}$ & B & $\mathbf{F}$ & B & $\mathbf{F}$ \\
\hline Fresh Reading & $6.8 \pm 0.03$ & $6.4 \pm 0.03$ & $6.8 \pm 0.03$ & $6.4 \pm 0.05$ & $6.8 \pm 0.03$ & $6.4 \pm 0.03$ & $6.8 \pm 0.02$ & $6.4 \pm 00.03$ \\
\hline After $24 \mathrm{H}$ & $6.8 \pm 0.04$ & $6.4 \pm 0.05$ & $6.8 \pm 0.03$ & $6.4 \pm 0.03$ & $6.7 \pm 0.02$ & $6.3 \pm 0.03$ & $6.7 \pm 0.01$ & $6.3 \pm 0.04$ \\
\hline After $72 \mathrm{H}$ & $6.7 \pm 0.03$ & $6.3 \pm 0.04$ & $6.7 \pm 0.03$ & $6.3 \pm 0.03$ & $6.6 \pm 0.05$ & $6.1 \pm 0.03$ & $6.5 \pm 0.02$ & $6.0 \pm 0.03$ \\
\hline After $7 \mathrm{D}$ & $6.6 \pm 0.02$ & $6.1 \pm 0.03$ & $6.5 \pm 0.04$ & $6.0 \pm 0.04$ & $6.4 \pm 0.01$ & $5.9 \pm 0.05$ & $6.3 \pm 0.02$ & $5.7 \pm 0.02$ \\
\hline After $14 \mathrm{D}$ & $6.5 \pm 0.03$ & $6.0 \pm 0.05$ & $6.4 \pm 0.05$ & $6.0 \pm 0.02$ & $6.3 \pm 0.0 .2$ & $5.8 \pm 0.04$ & $6.2 \pm 0.04$ & $5.6 \pm 0.03$ \\
\hline After $28 \mathrm{D}$ & $6.4 \pm 0.03$ & $5.8 \pm 0.04$ & $6.3 \pm 0.04$ & $5.7 \pm 0.03$ & $6.2 \pm 0.02$ & $5.5 \pm 0.03$ & $6.1 \pm 0.05$ & $5.3 \pm 0.05$ \\
\hline After $45 \mathrm{D}$ & $6.3 \pm 0.03$ & $5.7 \pm 0.03$ & $6.2 \pm 0.01$ & $5.6 \pm 0.04$ & $6.1 \pm 0.03$ & $5.4 \pm 0.01$ & $6.0 \pm 0.01$ & $5.2 \pm 0.04$ \\
\hline After $60 \mathrm{D}$ & $6.2 \pm 0.02$ & $5.6 \pm 0.04$ & $6.1 \pm 0.02$ & $5.5 \pm 0.01$ & $6.0 \pm 0.04$ & $5.4 \pm 0.02$ & $5.9 \pm 0.03$ & $5.3 \pm 0.03$ \\
\hline After $75 \mathrm{D}$ & $6.1 \pm 0.03$ & $5.4 \pm 0.05$ & $6.0 \pm 0.05$ & $5.3 \pm 0.02$ & $5.9 \pm .003$ & $5.1 \pm 0.03$ & $5.8 \pm 0.04$ & $5.0 \pm 0.04$ \\
\hline After $90 \mathrm{D}$ & $6.0 \pm 0.03$ & $5.3 \pm 0.05$ & $5.9 \pm 0.03$ & $5.2 \pm 0.01$ & $5.8 \pm 0.04$ & $5.0 \pm 0.04$ & $5.7 \pm 0.03$ & $5.0 \pm 0.05$ \\
\hline \multicolumn{9}{|l|}{ Conductivity } \\
\hline Fresh Reading & $173 \pm 0.03$ & $91 \pm 0.09$ & $173 \pm 0.1$ & $91 \pm 0.2$ & $173 \pm 0.01$ & $91 \pm 0.1$ & $173 \pm 0.05$ & $91 \pm 0.06$ \\
\hline After $24 \mathrm{H}$ & $174 \pm 0.02$ & $92 \pm 0.06$ & $175 \pm 0.06$ & $92 \pm 0.1$ & $178 \pm 0.02$ & $94 \pm 0.21$ & $179 \pm 0.05$ & $95 \pm 0.05$ \\
\hline After $72 \mathrm{H}$ & $179 \pm 0.02$ & $95 \pm 0.05$ & $180 \pm 0.07$ & $96 \pm 0.11$ & $181 \pm 0.03$ & $99 \pm 0.18$ & $184 \pm 0.04$ & $101 \pm 0.05$ \\
\hline After 7 D & $183 \pm 0.0 .2$ & $102 \pm 0.06$ & $184 \pm 0.1$ & $105 \pm 0.23$ & $191 \pm 0.02$ & $110 \pm 0.09$ & $199 \pm 0.06$ & $120 \pm 0.04$ \\
\hline After $14 \mathrm{D}$ & $186 \pm 0.01$ & $125 \pm 0.07$ & $188 \pm 0.06$ & $133 \pm 0.09$ & $193 \pm 0.02$ & $145 \pm 0.08$ & $201 \pm 0.03$ & $156 \pm 0.04$ \\
\hline After $28 \mathrm{D}$ & $193 \pm 0.04$ & $155 \pm 0.08$ & $189 \pm 0.08$ & $159 \pm 0.1$ & $199 \pm 0.03$ & $167 \pm 0.08$ & $206 \pm 0.03$ & $168 \pm .0 .05$ \\
\hline After $45 \mathrm{D}$ & $199 \pm 0.01$ & $159 \pm 0.09$ & $196 \pm 0.2$ & $161 \pm 0.21$ & $201 \pm 0.05$ & $169 \pm 0.06$ & $210 \pm 0.04$ & $170 \pm 0.05$ \\
\hline After $60 \mathrm{D}$ & $201 \pm 0.05$ & $169 \pm 0.09$ & $200 \pm 0.05$ & $164 \pm 0.06$ & $215 \pm 0.04$ & $178 \pm 0.06$ & $220 \pm 0.05$ & $177 \pm 0.03$ \\
\hline After 75 D & $207 \pm 0.01$ & $173 \pm 0.06$ & $209 \pm 0.06$ & $177 \pm 0.08$ & $218 \pm .0 .04$ & $191 \pm 0.05$ & $234 \pm 0.04$ & $188 \pm 0.08$ \\
\hline After $90 \mathrm{D}$ & $212 \pm 0.09$ & $186 \pm 0.08$ & $214 \pm 0.08$ & $189 \pm 0.07$ & $229 \pm 0.03$ & $197 \pm 0.06$ & $234 \pm 0.06$ & $202 \pm 0.07$ \\
\hline
\end{tabular}

mean \pm SD $(n=3)$

Table 2: Consistency index, flow index and confidence of fit at $8{ }^{\circ} \mathrm{C}, 25^{\circ} \mathrm{C}, 40{ }^{\circ} \mathrm{Cand} 40{ }^{\circ} \mathrm{C}+75 \% \mathrm{RH}$ of $\mathrm{Pyrus}$ communis emulgel, after $30 \mathrm{~d}$, after $60 \mathrm{~d}$ and after $90 \mathrm{~d}$

\begin{tabular}{|c|c|c|c|c|c|c|}
\hline After & Temperature & Fresh & $8^{\circ} \mathrm{C}$ & $25^{\circ} \mathrm{C}$ & $40^{\circ} \mathrm{C}$ & $40{ }^{\circ} \mathrm{C}+75 \% \mathrm{RH}$ \\
\hline \multirow[t]{3}{*}{$30 \mathrm{D}$} & Consistency Index & 2350 & 2200 & 2160 & 2010 & 1970 \\
\hline & Flow Index & 0.15 & 0.16 & 0.17 & 0.19 & 0.21 \\
\hline & Confidence of Fit & $93.2 \%$ & $94.7 \%$ & $95.8 \%$ & $96.6 \%$ & $97.3 \%$ \\
\hline After & Consistency Index & 2350 & 2264 & 2175 & 1940 & 1634 \\
\hline \multirow[t]{2}{*}{$60 \mathrm{D}$} & Flow Index & 0.15 & 0.16 & 0.17 & 0.20 & 0.23 \\
\hline & Confidence of Fit & $93.2 \%$ & $95.2 \%$ & $96.3 \%$ & $97.0 \%$ & $98.8 \%$ \\
\hline After & Consistency Index & 2350 & 2108 & 2056 & 1890 & 1542 \\
\hline \multirow[t]{2}{*}{$90 \mathrm{D}$} & Flow Index & 0.15 & 0.17 & 0.18 & 0.22 & 0.25 \\
\hline & Confidence of Fit & $93.2 \%$ & $95.9 \%$ & $96.8 \%$ & $97.1 \%$ & $98.4 \%$ \\
\hline
\end{tabular}

Table 3: Photomicrographs of freshly prepared Pyrus communis emulgel and after $12^{\text {th }}$ week in various storage conditions

\begin{tabular}{llll}
\hline Time period & $\mathbf{8}^{\circ} \mathbf{C}$ & $\mathbf{2 5}^{\circ} \mathbf{C}$ & $\mathbf{4 0}^{\circ} \mathbf{C}$ \\
\hline After $30 \mathrm{~d}$ & $16.0 \pm 0.30$ & $16.0 \pm 0.60$ & $16.4 \pm 0.50$ \\
After $60 \mathrm{~d}$ & $16.2 \pm 0.63$ & $16.4 \pm 0.72$ & $16.5 \pm 0.50$ \\
After $90 \mathrm{~d}$ & $16.6 \pm 0.60$ & $16.7 \pm 0.55$ & $16.8 \pm 0.30$ \\
\hline
\end{tabular}

mean \pm SD, RH=75\% Relative humidity, (for number of droplets $n=20$ )

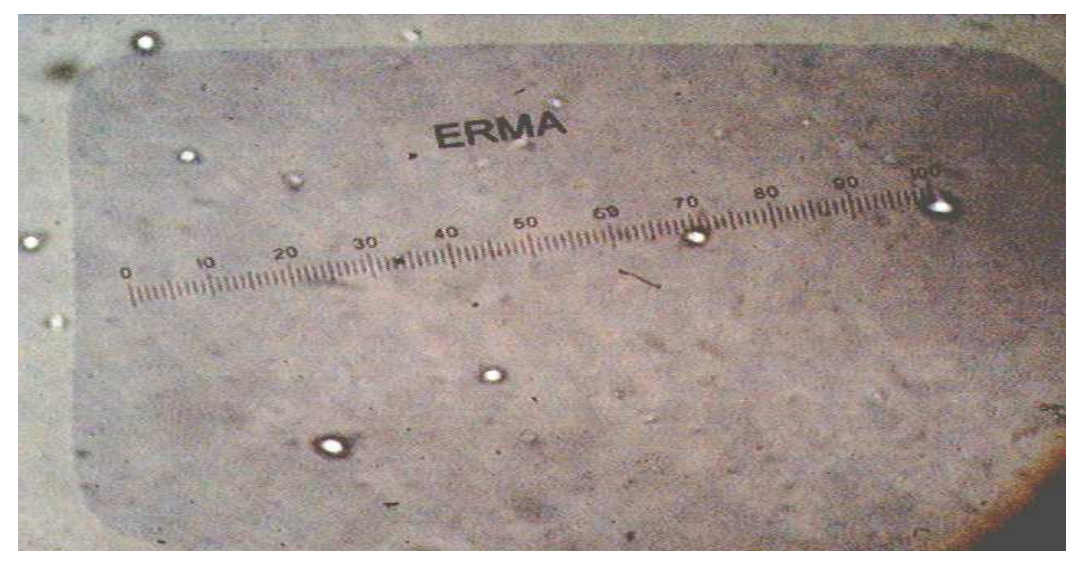

(A) Freshly prepared Pyrus communis emulgel 


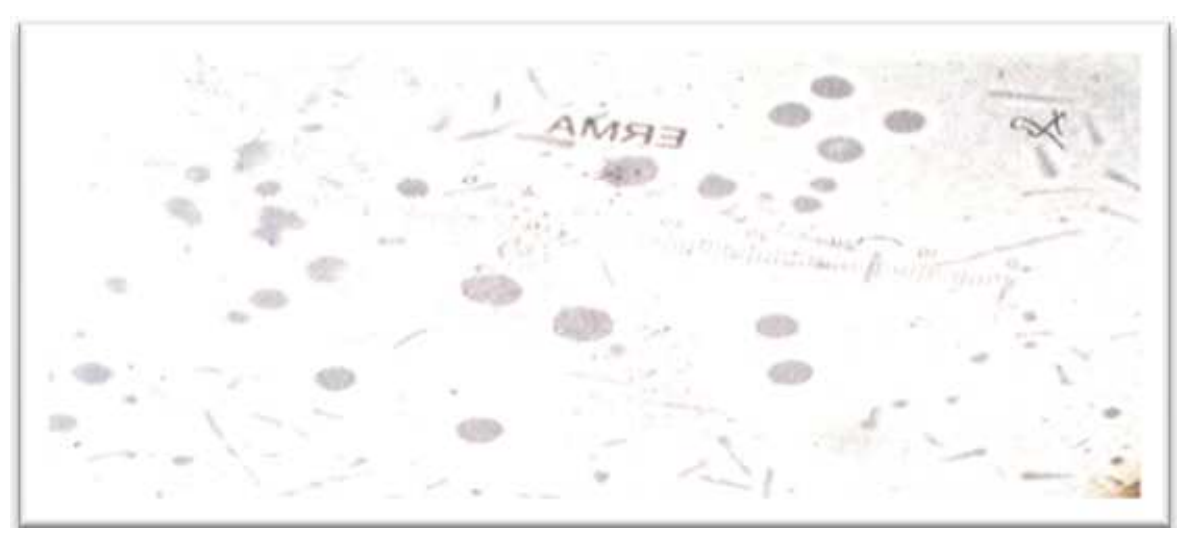

(B) After $12 \mathrm{w}$ of storage at $40{ }^{\circ} \mathrm{C}+75 \% \mathrm{RH}$

Fig. 1: Mean droplet diameter at various time intervals

\section{DISCUSSION}

Fruits are the source of energy. Not only they provide nutritional support to us, but also used as medicine. Orally and topically a lot of fruits are used in the external and internal dosage forms. In the present study, a new emulgel was prepared. A lot of researchers worked with fruit extracts for developing topical formulations [15]. Pyrus communis is one of the gifts of God. Fruit is full of healthy constituents like vitamin $\mathrm{C}$, carbohydrates, and minerals. Peoples use it orally for weight conscious peoples. Also used for diarrhea, hypertension and cardiac patients. Ladies used it for treatment of acne, lip balms and scrubbers. It is also good for hair. Until now no single pharmaceutical topical dosage form is present containing Pyrus communis extract. Normally formulations containing plant extracts have a stability issue. So in this study a new topical emulgel containing Pyrus communis extract is prepared. Emulgel formulation containing Pyrus communis extract and base (without Pyrus communis extract) is tested for its stability by keeping the formulation at $8{ }^{\circ} \mathrm{C}, 25{ }^{\circ} \mathrm{C}, 40{ }^{\circ} \mathrm{C}, 40{ }^{\circ} \mathrm{C}+75 \% \mathrm{RH}$ conditions. Formulation successfully qualified all conditions. The best storage temperature suggested is $25{ }^{\circ} \mathrm{C} \pm 5{ }^{\circ} \mathrm{C}$ as at $40{ }^{\circ} \mathrm{C}$ after $12 \mathrm{w}$ formulation showed a little degradation. The formulation has been tested for other in vitro tests like $\mathrm{pH}$, conductivity, centrifugation and rheology at these temperature conditions. For topical dosage forms $\mathrm{pH}$ should be in the range of 5.5. to 6.5 and the present formulation fit best in this range after $12 \mathrm{w}$ testing. The $\mathrm{pH}$ of the formulation was decreased with the passage of time due to the acidic nature of fruit extract. This supports the common use of this fruit as ladies in Pakistan use its fruit extract as household remedy for acne. Moreover, conductivity test was gradually increased in results of conductivity due to the movement of ions, but the formulation showed less conductivity as compared to the base formulation. The centrifugation test is an efficient stability test which physically used to measure the phase separation and liquefaction ability of formulation. The principle of this test was checked the effect of centrifugal force on the formulation by separating two different phases, i.e. these phases may be two immiscible liquids or one liquid and one insoluble solid. Phase separation of the formulation serves as a test to determine the stability of emulgel [16]. In our study the formulation described the slightly liquefaction after $75 \mathrm{~d}$ study periods due to high storage temperature $\left(40{ }^{\circ}\right.$ Cand $\left.40{ }^{\circ} \mathrm{C}+75 \% \mathrm{RH}\right)$. At higher temperatures, slight phase separation was occurring due to lowering of viscosity of oil phase under centrifugal force [16]. Both base and formulation showed similar behavior. This study showed that non-Newtonian, the pseudoplastic behavior of the formulation was not changed even under thermal stress over a period of time, describing the physical stability [17]. Rheology is concerned with the production and application of emulgel. Rheological parameters are very unique in determining the physical stability of the emulgel during the study period [18]. On the other hand, rheological results showed that a decreased occurred in the consistency Index of the formulation at various temperatures during storage conditions $[19,20]$. Droplet size is one of the most vital physical stability characteristics of the formulation which was used for topical formulation for cosmetic or dermal purposes. The small size of droplet was shown the less chance of formulation towards coalescence and sedimentation phenomena against gravitational forces [20]. In this study droplet size analysis showed that the emulgel had a small droplet size within the macro emulgel size range. The emulgel having Pyrus communis extract showed little increased in the droplet size of formulation at 8 ${ }^{\circ} \mathrm{C}$ and $25^{\circ} \mathrm{C}$ of storage conditions. Meanwhile, an increase in droplet diameter was observed at higher temperatures, i.e. $40{ }^{\circ} \mathrm{C}$ and 40 ${ }^{\circ} \mathrm{C} \pm 75 \% \mathrm{RH}$. It is stated that at higher temperature, the change in viscosity of continuous phase that viscosity decreased, which allow more frequent collision between the droplets and result in the increase of droplet size.

\section{CONCLUSION}

In this study the prepared w/o emulgel having Pyrus communis extract successfully qualify in vitro tests. The developed Pyrus Communis extract w/o emulgel containing good stability with proper resistance to phase separation, $\mathrm{pH}$, conductivity, pseudoplastic behavior and mean globule diameter in a narrow range over a specified period of time. New topical emulgel containing Pyrus Communis extract will be a good addition to pharmaceutical topical dosage forms. It is very necessary for the young researchers to work on the evidence base medicine and formulate new stable formulations. Such formulation developments will open new avenues in the healthcare system.

\section{ACKNOWLEDGMENT}

The authors would like to thank Professor Dr. Naveed Akhtar, Dean, Faculty of pharmacy and alternative medicine. The Islamia University of Bahawalpur, Bahawalpur for this admirable guidance as well as Prof. Dr. Saeed Ahmad, principal, UCCM, The Islamia University of Bahawalpur, for make possible easy access for conducting a part of some tests of this work.

\section{AUTHORS CONTRIBUTIONS}

Both Authors contributed equally in the designing, conducting and preparation of the manuscript of this research work.

\section{CONFLICT OF INTERESTS}

No conflicts of interest associated with this work

\section{REFERENCES}

1. Hancock JF, Lobos GA. Temperate fruit crop breeding: germplasm to genomics, Pears. Springer; 2008.

2. Pooja U, Poonam P. Comparison of antioxidant activity of peel and pulp part of the fruit pyrus pyrifolia. Chem Sci Trans 2015;4:1054-6.

3. Muhammad MU, Kamba AS, Abubakar L, Bagna EA. Nutritional composition of pear fruit (Pyrus communis). Afr J Food Sci Tech 2010;1:76-81. 
4. Velmurugan C, Anurag B. Total phenolic, flavonoids and tannin content of various extracts from Pyrus communis fruit. Int J Pharm Anal Res 2014;3:384-90.

5. Andrea CG, Angel GI, Maria IG. Comparative study of six pear cultivars in terms of their phenolic and vitamin $\mathrm{C}$ contents and antioxidant capacity. J Sci Food Agric 2003;83:995-1003.

6. Milind P, Arzoo. Why Is pear so dear. Int J Res Ayurv Pharm 2016;7:108-13.

7. Gudej J, Rychilnska I. Chemical compound in Pyrus communis L. flowers. Acta Polonica Pharm Drug Res 1999;56:237-9.

8. Sonia K, Nisar UR, Muhammad KS, Hamid M, Tanzila K, Raimar L. In vitro release of Indian penny wort, walnut, and turmeric from topical preparations using two different types of membranes. Dissolution Technol 2010;27:27-32.

9. Panwar AS, Updhyay N, Bairagi M, Gujar S, Darwhekar GN, Jain DK. Emulgel a review. Asian J Pharm Life Sci 2011;1:333-43.

10. Rieger MM, Lachman L, Lieberman HA, Kanig JL. The theory and practice of industrial pharmacy. $3^{\text {rd }}$ ed. PA Lea and Febiger; 1986.

11. Gupta A, Mishra AK, Singh AK, Gupta V, Bansal P. Formulation and evaluation of topical gel of diclofenac sodium using different polymers. Drug Invent Today 2010;2:250-3.

12. Guaratini T, Gianeti MD, Campos PM. Stability of cosmetic formulation containing esters of vitamins $\mathrm{E}$ and $\mathrm{A}$ : chemical and physical aspects. Int J Pharm 2006;327:12-6.
13. Yang Y, Lesser ME, Sher AA, Mcclements DJ. Formulation and stability of emulsion using a natural small molecules surfactant: quillaja saponin. Food Hydrocoll 2013;30:589-96.

14. Masson DS, Morais GG, Morais JM, Andrade FF, Santos OD, Oliverira WP. Polyhydroxy alcohols and peach oil addition influence on liquid crystal formation and rheological behavior of o/w emulsions. J Disper Sci Technol 2005;26:463-8.

15. Alisha P, Rashmi M. Formulation and evaluation of a photo protectant cream containing phyllanthus emblica extract phospholipid complex. J Pharmacog Phytochem 2015;4:232-40.

16. Binks BP, Rocher A. Effects of temperature on water-in-oil emulsions stabilized solely by wax microparticles. J Colloid Interface Sci 2009;335:94-104.

17. Korhonen M, Hellen L, Hirvonen J, Yliruusi J. Rheological properties of creams with four different surfactant combinations effect of storage time and conditions. Int J Pharm 2001;221:187-96.

18. Gaspar L, Campose PM. Rheological behavior and the SPF of Sunscreens. Int J Pharm 2003;250:35-44.

19. Guaratini T, Gianeti MD, Campos PM. Stability of cosmetic formulation containing esters of vitamins $\mathrm{E}$ and a: chemical and physical aspects. Int J Pharm 2006;327:12-6.

20. Sultana SS, Parveen P, Srirekha M, Deepthi K, Sowjanya, Devi SA. Emulgel-a novel surrogate approach for transdermal drug delivery system. Indo Am J Pharm Res 2014;4:5250-65. 